\title{
Real-Time Road Traffic Management Using Floating Car Data
}

\section{Angela-Aida K. Runyoro ${ }^{1}$ and Jesuk Ko ${ }^{2}$}

${ }^{1}$ School of Computational and Communications Science and Engineering, Nelson Mandela African Institute of Science and Technology (NM-AIST), Arusha, Tanzania

${ }^{2}$ Department of Healthcare Management, Gwangju University, Gwangju, Korea

\section{ljfis}

Received: Nov. 13, 2013

Revised : Dec. 20, 2013

Accepted: Dec. 23, 2013

Correspondence to: Angela-Aida K. Runyoro (runyoroa@nm-aist.ac.tz)

(CThe Korean Institute of Intelligent Systems

(c) This is an Open Access article distributed under the terms of the Creative Commons Attribution Non-Commercial License (http://creativecommons.org/licenses/ by-nc/3.0// which permits unrestricted noncommercial use, distribution, and reproduction in any medium, provided the original work is properly cited.

\begin{abstract}
Information and communication technology (ICT) is a promising solution for mitigating road traffic congestion. ICT allows road users and vehicles to be managed based on real-time road status information. In Tanzania, traffic congestion causes losses of TZS 655 billion per year. The main objective of this study was to develop an optimal approach for integrating real-time road information (RRI) to mitigate traffic congestion. Our research survey focused on three cities that are highly affected by traffic congestion, i.e., Arusha, Mwanza, and Dar es Salaam. The results showed that ICT is not yet utilized fully to solve road traffic congestion. Thus, we established a possible approach for Tanzania based on an analysis of road traffic data provided by organizations responsible for road traffic management and road users. Furthermore, we evaluated the available road information management techniques to test their suitability for use in Tanzania. Using the floating car data technique, fuzzy logic was implemented for real-time traffic level detection and decision making. Based on this solution, we propose a RRI system architecture, which considers the effective utilization of readily available communication technology in Tanzania.
\end{abstract}

Keywords: Floating car data, Real-time road information, Traffic congestion

\section{Introduction}

Traffic congestion is major issue that affects modern life in big cities throughout the world. It impedes our mobility, but also pollutes the air, wastes fuel, and hampers economic growth. For example, the total loss attributable to traffic problems in Tanzania is estimated to be TZS 655 billion per year [1], which is not economical, particularly in developing countries such as Tanzania that face other developmental challenges. It is considered that improving a country's transportation system solely involves building new roads or repairing aging infrastructures, but the future of transportation lies not only in concrete and steel, because it also needs the application of information and communication technology (ICT). ICT allows transportation system elements (vehicles, roads, traffic lights, and message signs) to become intelligent by embedding them with microchips and sensors, which facilitate their communication via wireless technology $[2,3]$.

Real-time road information (RRI) is used to reduce congestion by helping road users to make decisions based on ground information. RRI changes the behavior of drivers, which is important for solving traffic congestion. 
RRI provides alternative options to road users, which can be divided broadly into time, route, and mode of travel alternatives [4].

Several studies have implemented RRI systems. however collecting real-time road data for direct application by users remains a challenge $[5,6]$. There are many methods for collecting real-time data but most are expensive in terms of installation and maintenance. In the present study, we established that the floating car data (FCD) method is cost effective and it would allow the full utilization of readily available technologies (especially mobile phones) in Tanzania. In FCD, the data are collected and processed by a centralized server, which distributes information to road users via several interfaces, including web, radio, television, and mobile phones.

The term intelligent transportation system (ITS) has emerged in the past decade to describe research into technologies that can improve the throughput of transportation systems. ITS provide new information-based services to guide transportation system users [7].

A previous study [8] reported that there are two general categories of information for road users: pre-trip information and en route road information. The availability of this information allows road users to save time, cost, and avoid congestion by making better informed transport choices. RRI services have been implemented in several countries and they are essential components of advanced traveler information systems (ATIS) [5]. ATIS use several techniques that allow road users to receive roadway, transport network, and other types of information, which are important for their trip. Moreover, RRI allows users to decide whether to travel and to select destinations, the timing of journeys, the transport mode, the route, or the transit line [9].

The general aim of the present study was to determine the optimal approach for managing RRI to mitigate traffic congestion. The specific objectives were:

1) to investigate and evaluate the available technologies for road information integration and management; and

2) to design a RRI system architecture using readily available technology.

\section{Related Work}

Transportation systems apply several existing and evolving communications technologies for data collection and cleansing, data fusion, and integration, as well as data distribution. The raw data are collected from the roads, before they are filtered and analyzed in the back-end system, and then disseminated to road users. Road data collection techniques employ two data collection methods depending on their functionalities: intrusive and non-intrusive methods [10].

\subsection{Intrusive Methods}

Intrusive methods basically utilize a data recorder and sensors placed in the road [10]. Some studies have used these methods for road data collection to estimate the traffic state. Intrusive methods collect road data using traffic control techniques, such as magnetic loop detectors buried in the road and infra-red and radar sensors at the roadside. These sensors provide limited traffic information and they require separate systems for traffic counting and traffic surveillance. Inductive loop detectors are a cost-effective solution, but they have a high failure rate if they are installed on poor road surfaces, while they can reduce the pavement life and obstruct traffic during maintenance and repair [11]. Infrared sensors are affected to a greater degree by fog compared with video cameras and the sensor does not respond if the vehicle position is not in alignment with the infrared rays $[11,12]$.

\subsection{Non-Intrusive Methods}

Non-intrusive methods are based on remote observations and they are used adjacent to roadways, where they have minimal interaction with the traffic flow [10]. These techniques use video cameras to record vehicle numbers, vehicle types, and the speed of vehicles with different video techniques, although these systems can be sensitive to meteorological conditions. Previous studies [10,13] have also reported the use of microwave radar to count vehicle numbers, record speeds, and for simple vehicle classification, where this method is not affected by the weather conditions. Doppler and microwave radar systems transmit lowenergy radiation and they determine the time delay between transmission and reflection to calculate the distance to a vehicle. These methods are capable of measuring the presence and speed of vehicles but they are generally incapable of classification.

\subsection{FCD Technique}

In this study, we selected the FCD technique, which is also known as floating cellular data and it is defined in [14]. FCD is a traffic information gathering method, where cars act as mobile sensor nodes because they are equipped with global positioning system (GPS)-enabled mobile phones. Traffic information services based on FCD are already in use in Japan 


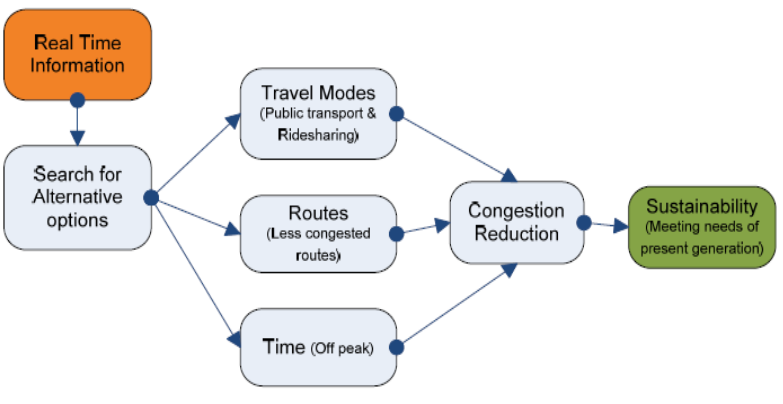

Figure 1. Role of real-time road information in road traffic management [4].

and the European Union (EU). In contrast to other traffic data collection techniques with high installation and maintenance costs (e.g., automated vehicle identification systems, video cameras, inductive loops, and radar-based sensors), FCD uses GPS, global system for mobile communication (GSM)/general packet radio service (GPRS), and universal mobile telecommunication system (UMTS) networks so there are no requirements for instrumentation set up on the roadway [15]. This facilitates the cost-effective implementation of the FCD by utilizing readily available mobile phones and the cellular network infrastructure. This pre-existing information is exchanged within the infrastructures of the GSM and UMTS networks, which solves the problem of a lack of resources [16].

Previous studies $[10,14]$ have noted that FCD aims to collect real-time traffic data by locating a vehicle via GPS-enabled mobile phones, which are carried in the vehicles throughout the entire road network. Thus, these mobile phones act as sensors in the road network. Data on the location, speed, and direction of travel of cars are sent anonymously to a central processing unit. After the collection and extraction of data, useful information is redistributed to road users as pre-trip or en route information.

Thus, the FCD technique is the major component of the RRI services we selected to mitigate traffic congestion in Tanzania. RRI services will contribute to reducing the economic losses caused by traffic congestion by optimizing the use of readily available electronic devices. Figure 1 illustrates the role of RRI, where the availability of information facilitates the search for alternative options. These options include the selection of travel modes, routes, and timing, which lead to reduced congestion.

\section{Proposed RRI System Architecture}

Our proposed RRI system architecture considers real-time road traffic data collection, processing, and dissemination. Readily

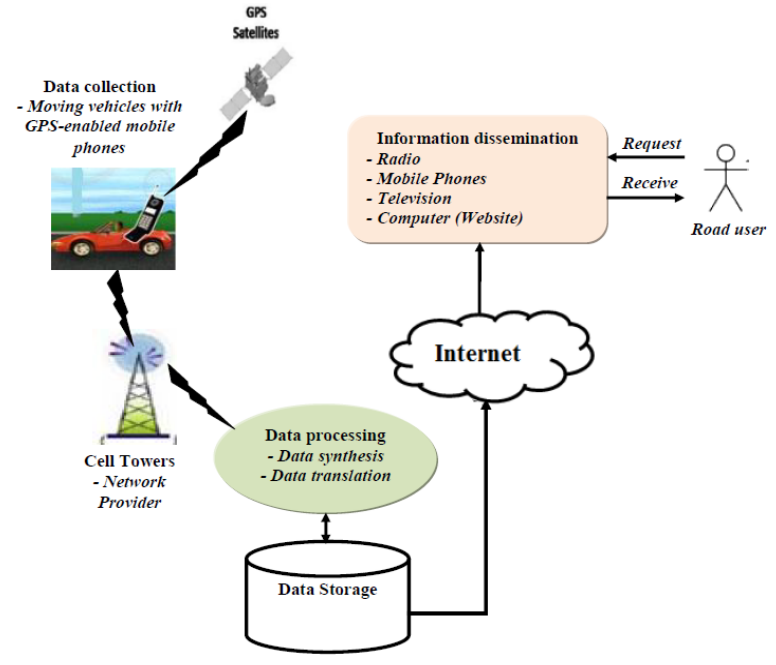

Figure 2. Proposed real-time road information system architecture.

available communication technologies and infrastructure are integrated to manage the RRI. GPS-enabled mobile phones are used as moving sensors, as explained in the previous section. Mobile phones are used for information dissemination, in addition to other techniques such as radio, television, and the Internet. As shown in Figure 2 the main components of the proposed architecture are:

1) data collection,

2) data processing and storage, and

3) information dissemination.

\subsection{Data Collection}

Road traffic data can be collected using GPS-enabled mobile phones, as explained previously [17]. Most GPS-enabled mobile phones are embedded with a GPS chip-set, which is capable of generating a time-stamped geo-position (latitude, longitude, and altitude). The instantaneous speed can be determined based on the time and position data. For road traffic data collection, we decided to use active GPS tracking, which automatically sends information from the GPS device to a central tracking portal or system in real-time. This type of system is better for monitoring the road status, such as the presence of vehicles at a specific location, their speed, the number of vehicles, and the travelling time between points.

Thus, we developed software that transforms GPS-enabled mobile phones into mobile traffic probes, which provide realtime data on the traffic flow and travel times. The software was installed in all of the phones that participated as traffic probes. We employed the virtual trip lines (VTL) strategy for 
Table 1. Input data fuzzy set

\begin{tabular}{|c|c|c|c|c|c|}
\hline \multicolumn{6}{|c|}{ Speed membership functions } \\
\hline $\begin{array}{l}\text { Speed range } \\
(\mathrm{km} / \mathrm{h})\end{array}$ & $0-20$ & $0-40$ & $20-60$ & $40-80$ & $>60$ \\
\hline $\begin{array}{l}\text { Type of } \\
\text { membership }\end{array}$ & $\begin{array}{l}\text { Very } \\
\text { slow } \\
\text { (VS) }\end{array}$ & $\begin{array}{l}\text { Slow } \\
(\mathrm{S})\end{array}$ & $\begin{array}{l}\text { Mediun } \\
\text { (M) }\end{array}$ & $\begin{array}{l}\text { Fast } \\
(\mathrm{F})\end{array}$ & $\begin{array}{l}\text { Very } \\
\text { fast } \\
(\mathrm{VF})\end{array}$ \\
\hline \multicolumn{6}{|c|}{ Number of vehicles (density) membership functions } \\
\hline $\begin{array}{l}\text { Density range } \\
\text { (vehicle } / \mathrm{km} / \mathrm{lane} \text { ) }\end{array}$ & $0-15$ & $0-30$ & $15-45$ & $30-60$ & $>45$ \\
\hline $\begin{array}{l}\text { Type of } \\
\text { membership }\end{array}$ & $\begin{array}{l}\text { Very } \\
\text { low }\end{array}$ & Low & Medium & High & $\begin{array}{l}\text { Very } \\
\text { high }\end{array}$ \\
\hline
\end{tabular}

better data quality management and to ensure the privacy of the mobile phone users [18]. The VTL sets data collection points, which yield traffic information but do not detect a user's personal information. As vehicles pass through the set VTL, the phones automatically send anonymous phone ID, time, and location readings to a data processing server. The collected data are then integrated and used as the input for the data processing module, which estimates the traffic flow.

\subsection{Data Processing}

Fuzzy inference processing was used to formulate the mapping from a given input to an output using fuzzy logic, which was simulated to handle the traffic data processing. The test scenario was Morogoro road, which is the main highway that connects all of the feeder roads to Dar es Salaam city center. The inputs of the data processing module included the number of vehicles (density) and the vehicle speeds, which were recorded by the data collection module. The output from the data processing module was the level of congestion (LOC). The Mamdani fuzzy inference system was simulated using MATLAB R2007a to develop the fuzzy model. Two input variables, one output variable, and 25 fuzzy rules were set. The fuzzy subsets for the input and output variables were derived as shown in Tables 1 and 2 .

Figure 3 shows a graphical presentation of the variables in the simulation. The fuzzy sets overlap as a natural consequence of their elastic boundaries. These overlaps permit the implementation of a realistic and functional semantic mechanism to define the nature of a variable when various data values were assumed, and they also allow smooth and coherent transitions among states.
Table 2. Output data fuzzy set

\begin{tabular}{lccccc}
\hline $\begin{array}{l}\text { Level of } \\
\text { congestion } \\
\text { range }\end{array}$ & $0-5$ & $0-10$ & $5-15$ & $10-20$ & $>15$ \\
\hline $\begin{array}{l}\text { Type of } \\
\text { member- } \\
\text { ship }\end{array}$ & $\begin{array}{c}\text { Free- } \\
\text { flowing }\end{array}$ & $\begin{array}{l}\text { Slow- } \\
\text { moving }\end{array}$ & $\begin{array}{c}\text { Medium Conges- } \\
\text { tion } \begin{array}{c}\text { Heavy } \\
\text { conges- } \\
\text { tion }\end{array}\end{array}$ \\
\hline
\end{tabular}

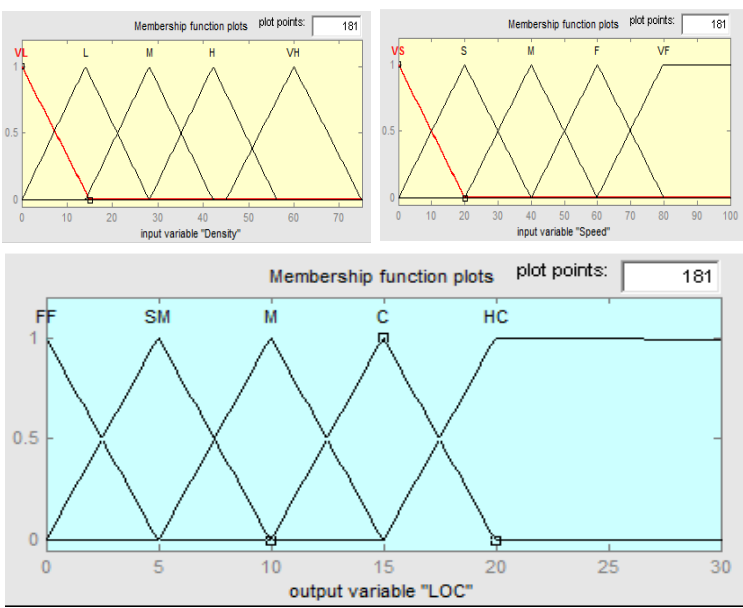

Figure 3. Membership function plots for inputs (density and speed) and outputs. LOC, level of congestion.

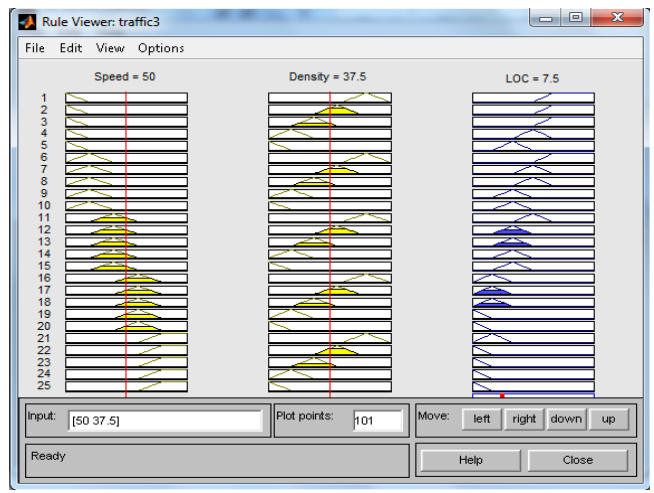

Figure 4. Rule viewer.

The rule viewer in Figure 4 shows an example of a calculation at a specific time in great detail, which represents a micro-view of the fuzzy inference system.

Based on the rules set for the membership functions, a threedimensional surface graphical representation is generated, as shown in Figure 5. The three graph axes combine the input and output variables for the general model setup, which indicate that the LOC increases as the density increases and the speed decreases.

The calculated LOC is then map-matched to determine the 


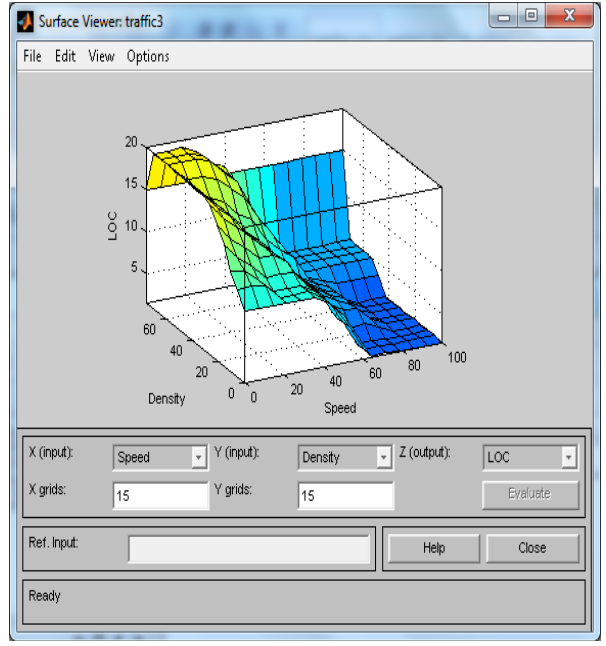

Figure 5. Three-dimensional surface curve used as the data processing model.

real situation on the road. These signals are processed and translated into road information, which is stored in the database.

\subsection{Information Dissemination}

Users access the RRI from a storage module, where various technologies such as mobile phones and the Internet are used to request and receive the information directly. Television and radio operators may also access the information and disseminate it as appropriate. This arrangement allows road users to dynamically access the RRI via any media capable of receiving information. To ensure that the system is flexible, the architecture requires that road users send a request before they receive the RRI for specific lanes.

\section{Analysis of Road Traffic Management in the Cities}

Our study was conducted in Dar es Salaam, Mwanza, and Arusha. These cities are affected the most severely by road traffic congestion [19]. Three organizations in each city are responsible for road traffic management: traffic police, municipal councils, and Tanzania National Roads Agency (TANROADS). Furthermore, drivers and non-drivers were included in the survey. Primary data were collected to identify the current traffic congestion situation and to understand the factors that affect the procedures implemented to alleviate congestion. Questionnaires were developed and sent to town planners, road engineers, traffic police officers, and road users (drivers and non-drivers). In total, 90 subjects were contacted at the three organizations

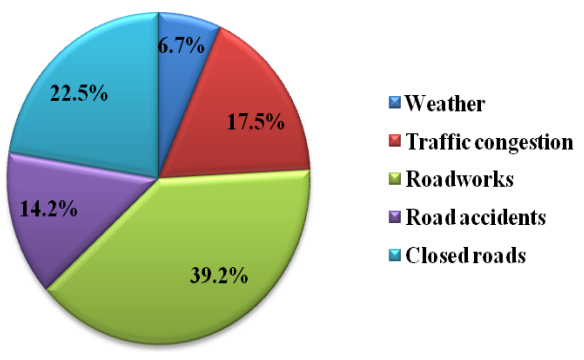

Figure 6. Disseminated road information.

and 86 responded. For the road users, the sample size was calculated using Eq. (1) [20]:

$$
s=\frac{X^{2} N P(1-P)}{d^{2}(N-1)+X^{2} P(1-P)},
$$

where $s$ is the required sample size, $X^{2}$ is the chi-square table value for the first degree of freedom at the desired confidence level (3.841), $N$ is the population size, $P$ is the population proportion (assumed to be 0.50 because this would provide the maximum sample size), and $d$ is the degree of accuracy expressed as a proportion (0.05).

In the three cities, 1,200 road users were contacted but only 1,100 returned their questionnaires. The data were analyzed using SPSS (SPSS Inc., Chicago, IL, USA). Descriptive analyses were generated to identify the frequency of responses to the question items. Fisher's exact test was used to determine the significant effects of road information dissemination on traffic congestion control. Significant differences between the dependent and independent variables were accepted at $p<0.05$.

\subsection{Traffic Flow Management}

The results showed that the organizations manage road traffic flow by disseminating road traffic information to road users, but the information was static. The percentages of disseminated road information are shown in Figure 6, i.e., information related to road construction work in progress (39.2\%), closed/faulty roads (22.5\%), traffic congestion (17.5\%), road accidents (14.2\%), and weather (6.7\%).

The manually disseminated road information did not reduce the problem.

The results showed that road users would prefer to request and receive RRI, as shown in Table 3. The preferred methods for requesting/retrieving road information were radio $=31.4 \%$, mobile phones $=30.9 \%$, and $<20 \%$ preferred other methods, including websites and television. 
Table 3. Preferred methods for requesting/retrieving real-time road information

\begin{tabular}{lcc}
\hline $\begin{array}{l}\text { Method of } \\
\text { information } \\
\text { delivery }\end{array}$ & $\mathrm{N}$ (frequency) & Percentage \\
\hline Internet/website & 301 & $14.7 \%$ \\
Mobile phone & 631 & $30.9 \%$ \\
Radio & 641 & $31.4 \%$ \\
Television & 385 & $18.8 \%$ \\
Others & 85 & $4.2 \%$ \\
\hline
\end{tabular}

The outcome variable "road traffic congestion" was affected by many factors. These factors included a large number of vehicles, low road capacity, poor traffic management, and poor road information dissemination. We calculated the $p$-value using Fisher's exact and Spearman's rank correlation coefficient $r$ to test the associations between each factor and road traffic congestion, as shown in Table 4.

All of the factors had positive correlations with traffic congestion, but road information dissemination had the strongest correlation compared with the other factors $(p=0.017)$. There was a positive correlation between the variables $(r=0.261)$. These values indicated that the dissemination of road status information was very important to road users. The other factors had no significant effects $(p>0.05)$. The road users indicated that they would prefer to receive travel information in advance so that they could manage their travelling time and transportation mode. This shows that the provision of more road information gives more control over traffic, thereby reducing congestion.

\subsection{Discussion}

Our traffic management findings show that there is a need for RRI dissemination. Static information provision is not capable of making an impact on the problem. We found that there was a positive correlation between information dissemination and congestion control. Congestion means that road users experience delays in reaching their home or workplace, and they may fail to reach their appointments on time [21]. One respondent stated, "we arrived late at home and failed to help our children in their homework."

The government has implemented manual procedures to reduce the problem but these have proved unsuccessful [22]. The types of information disseminated to mitigate traffic conges-
Table 4. Factors associated with road traffic congestion $(\mathrm{N}=86)$ Road traffic congestion

\begin{tabular}{|c|c|c|c|c|c|}
\hline Factors & Yes & No & $\begin{array}{l}\text { Number } \\
\text { of } \\
\text { respon- } \\
\text { dents }\end{array}$ & $\begin{array}{l}\text { Fisher's } \\
\text { exact } \\
\text { test } p \text { - } \\
\text { value }\end{array}$ & $\begin{array}{l}\text { Spearman's } \\
\text { rank } \\
\text { correlation } \\
\text { coefficient } r\end{array}$ \\
\hline \multicolumn{6}{|c|}{ Number of vehicles on the road } \\
\hline Agree & $\begin{array}{c}56 \\
(71.8 \%)\end{array}$ & $\begin{array}{c}22 \\
(28.2 \%)\end{array}$ & $\begin{array}{c}78 \\
(90.7 \%)\end{array}$ & 0.686 & 0.059 \\
\hline Disagree & $\begin{array}{c}5 \\
(62.5 \%)\end{array}$ & $\begin{array}{c}3 \\
(37.5 \%)\end{array}$ & $\begin{array}{c}8 \\
(9.3 \%) \\
\end{array}$ & & \\
\hline
\end{tabular}

\begin{tabular}{lccccc}
\multicolumn{6}{l}{ Road capacity } \\
\hline Agree & 45 & 16 & 61 & 0.435 & 0.098 \\
& $(73.8 \%)$ & $(26.2 \%)$ & $(70.9 \%)$ & &
\end{tabular}

\begin{tabular}{cccc} 
Disagree & 16 & 9 & 25 \\
& $64.0 \%)$ & $(36.0 \%)$ & $(29.1 \%)$ \\
\hline
\end{tabular}

\begin{tabular}{lccccc}
\multicolumn{1}{l}{ Traffic control } \\
\hline Agree & $\begin{array}{c}46 \\
(73.0 \%)\end{array}$ & $\begin{array}{c}17 \\
(27.0 \%)\end{array}$ & $\begin{array}{c}63 \\
(73.3 \%)\end{array}$ & 0.593 & 0.076
\end{tabular}

\begin{tabular}{cccc} 
Disagree & 15 & 8 & 23 \\
$(65.2 \%)$ & $(34.8 \%)$ & $(26.7 \%)$ \\
\hline
\end{tabular}

Disseminated road information

\begin{tabular}{lccccc}
\hline Agree & 21 & 50 & 71 & 0.017 & 0.261 \\
& $(29.6 \%)$ & $(70.4 \%)$ & $(82.6 \%)$ & & \\
Disagree & 0 & 15 & 15 & & \\
& $(0 \%)$ & $(100 \%)$ & $(17.4 \%)$ & & \\
\hline
\end{tabular}

tion are shown in Figure 6. These efforts require additional support based on ICT. As shown in Table 3, most road users would prefer to request/retrieve road information using a radio or a mobile phone. This indicates the possibility of accessing mobile phones to implement the proposed FCD technique. These devices are readily available and used by most road users. A previous study [23] estimated that there were 27.4 million subscribers to mobile networks in Tanzania in December 2012.

At present, road information is disseminated manually, but it has contributed little to reducing traffic congestion. We found that the information disseminated in the three main cities of Tanzania was focused only on recurring congestion. This information was not automated and it was disseminated using static wooden signs. This approach fails to provide road users with RRI that might improve the congestion situation. Thus, the RRI management system should include recurring and non-recurring road problems. In this study, we considered these types of situations during the development of our proposed architecture 
because of their importance.

\section{Conclusion and Future Works}

In this study, we considered the application of RRI to congestion control. The FCD method was used for real-time road status data collection. This method is suitable for Tanzania because it is a developing country that lacks a traffic monitoring infrastructure, but the penetration of mobile phones is increasing rapidly in the population. Thus, we proposed a RRI system architecture, which considers the effective utilization of readily available communication technology in Tanzania to facilitate congestion control. We also considered the possible methods road users would prefer to use to access RRI. The implementation of the proposed architecture will contribute to congestion control in Tanzanian cities. In the future, we will implement the system by coding and interfacing the requisite modules.

\section{Conflict of Interest}

No potential conflict of interest relevant to this article was reported.

\section{References}

[1] J. N. Katala, "The cost of traffic congestion and accidents to the economy in Tanzania," Available http://www.iekenya.org/download/Jumbe\%20N.Katala\% 20\%5bThe \%20cost $\% 20$ of\%20traffic $\% 20$ congestion..... $\% 5$ dDART.pdf

[2] H. J. Hong, Y. S. Ro, H. J. Kang, Y. S. Suh, and T. H. Kim, "Development of the simulation tool for the modeling and traffic control of a AGV system," Journal of Korean Institute of Intelligent Systems, vol. 14, no. 4, pp. 499-505, Jul. 2004. http://dx.doi.org/10.5391/JKIIS.2004.14.4.499

[3] S. Ezell, Explaining International IT Application Leaderhip: Intelligent Transportation Systems, The Information Technology \& Innovation Foundation, 2010. Available http://www.itif.org/files/2010-1-27-ITS_Leadership.pdf

[4] N. Vijayakumar and G. Mehendiratta, "Role of ICT in Sustainable transportation-focus on reducing traffic congestion,” M.S. thesis, School of Business and Informatics, University of Bors, Borøas, Sweden, 2011.

[5] H. Bar-Gera, "Evaluation of a cellular phone-based system for measurements of traffic speeds and travel times: a case study from Israel," Transportation Research Part C: Emerging Technologies, vol. 15, no. 6, pp. 380-391, Dec. 2007. http://dx.doi.org/10.1016/j.trc.2007.06.003

[6] T. Neumann, "Floating-car data for urban traffic monitoring-a new approach, its applications and future visions," Available http://elib.dlr.de/64050/1/ FCDforUrbanTrafficMonitoring.pdf

[7] P. Bergougnoux, "Editorial: geographic information systems and intelligent transportation systems," GeoInformatica, vol. 4, no. 2, pp. 123-125, Jun. 2000. http: //dx.doi.org/10.1023/A:1009884521096

[8] J. Noonan and O. Shearer, Intelligent Transportation Systems Field Operational Test Cross-Cutting Study Advance Traveler Information Systems [Report no. FHWA-JPO99-038], Available http://www.fhwa.dot.gov/publications/ research/operations/its/jpo99038/fotatis.pdf

[9] J. A. Bottom, "Consistent anticipatory route guidance," Ph.D. dissertation, Massachusetts Institute of Technology, Cambridge, MA, 2000.

[10] G. Leduc, Road Traffic Data: Collection Methods and Applications [Technical note: JRC 47967], Seville, Spain: European Commission, Joint Research Centre, Institute for Prospective Technological Studies, 2008.

[11] U. Nagaraj, J. Rathod, P. Patil, S. Thakur, and U. Sharma, "Traffic jam detection using image processing," International Journal of Engineering Research and Applications, vol. 3, no. 2, pp. 1087-1091, Mar./Apr. 2013.

[12] Y. P. Singh and P. K. Mittal, "Analysis and designing of proposed intelligent road traffic congestion control system with image mosaicking technique," International Journal of IT, Engineering and Applied Sciences Research, vol. 2, no. 4, pp. 27-31, Apr. 2013.

[13] E. Minge, J. Kotzenmacher, and S. Peterson, Evaluation of Non-Intrusive Technologies for Traffic Detection [Report no. MN/RC 2010-36], Available http://www.lrrb.org/ media/reports/201036.pdf

[14] D. Ayala, L. Jie, O. Wolfson, N. Rishe, and M. Tanizaki, "Communication reduction for floating car data-based traffic information systems," in Proceedings of the 2nd International Conference on Advanced Geographic Information Systems, Applications, and Services, St. Maarten, 
The Netherlands Antilles, Febrary 10-16, 2010, pp. 44-51. http://dx.doi.org/10.1109/GEOProcessing.2010.14

[15] C. De Fabritiis, R. Ragona, and G. Valenti, "Traffic estimation and prediction based on real time floating car data," in Proceedings of the 11th International IEEE Conference on Intelligent Transportation Systems, Beijing, China, December 10-12, 2008, pp. 197-203. http: //dx.doi.org/10.1109/ITSC.2008.4732534

[16] D. Gundlegrd and J. M. Karlsson, "Road traffic estimation using cellular network signaling in intelligent transportation systems," in Wireless Technologies in Intelligent Transportation Systems, M. T. Zhou, Y. Zhang, and L. T. Yang, Eds. New York, NY: Nova Science Publishers, 2010, pp. 361-392.

[17] J. C. Herrera, D. B. Work, R. Herring, X. Ban, Q. Jacobson, and A. M. Bayen, "Evaluation of traffic data obtained via GPS-enabled mobile phones: the mobile century field experiment," Transportation Research Part C: Emerging Technologies, vol. 18, no. 4, pp. 568-583, Aug. 2010. http://dx.doi.org/10.1016/j.trc.2009.10.006

[18] B. Hoh, M. Gruteser, R. Herring, J. Ban, D. Work, J. C. Herrera, A. M. Bayen, M. Annavaram, and Q. Jacobson, "Virtual trip lines for distributed privacy-preserving traffic monitoring," in Proceedings of the 6th International Conference on Mobile Systems, Applications, and Services Breckenridge, CO, 2008, pp. 15-28. http: //dx.doi.org/10.1145/1378600.1378604

[19] G. D. Mrema, “Traffic congestion in Tanzanian major cities: causes, impact and suggested mitigations to the problem," in Proceedings of 26th National Conference on Challenges in Addressing Traffic Congestion and Enhancing Road Safety for National Development, Arusha, Tanzania, 2011.

[20] R. V. Krejcie and D. W. Morgan, "Determining sample size for research activities," Educational and Psychological Measurement, vol. 30, no. 3, pp. 607-610, Sep. 1970. http://dx.doi.org/10.1177/001316447003000308

[21] Y. S. Hong and M. B. Choi, "Forecasting of traffic situation using internet," Journal of Korean Institute of Intelligent Systems, vol. 13, no. 3, pp. 300-309, Jun. 2003. http://dx.doi.org/10.5391/JKIIS.2003.13.3.300
[22] P. K. Mzee and E. Demzee, "ITS applications in developing countries: a case study of bus rapid transit and mobility management strategies in Dar es Salaam-Tanzania,' in Intelligent Transportation Systems, A. Abdel-Rahim, Ed., 2012, chapter 3. http://dx.doi.org/10.5772/27557

[23] Tanzania Telecommunication Regulatory Authority (TCRA), "Quarterly telecom statistics: quarter 2 (December 2010) report," Available http://www.egov.go.tz/ egov_uploads/documents/telecomStatsDec10_sw.pdf

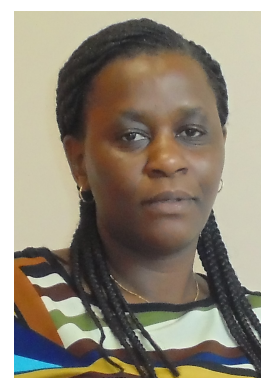

Angela- Aida K. Runyoro received her Postgraduate Diploma in Managerial Control and Management Information Systems from the Maastricht School of Management in Netherlands, and her Master's degree in Computer Science from the University of Dar es salaam in Tanzania. She also obtained her Advanced Certificate in Information Technology for African Business from Inwent in German, and her Bachelor degree in Electrical Engineering from the University of Dar es salaam, respectively. She is a Ph.D. candidate in the School of Computational and Communications Science and Engineering at the Nelson Mandela African Institute of Science and Technology (NM-AIST), Arusha in Tanzania. Her research interests include systems analysis and design, integrated systems development; IT projects management and traffic control systems, etc.

E-mail: runyoroa@nm-aist.ac.tz

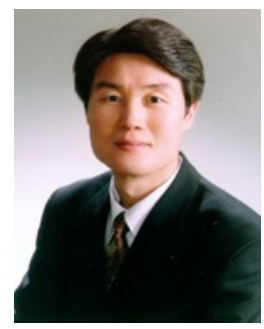

Jesuk Ko received his Ph.D. degree in Systems Engineering from Royal Melbourne University of Technology (RMIT) in Australia, and his M.Eng.Sc. degree in Industrial Engineering from Pohang University of Science and Technology (POSTECH) in Korea, respectively. He was a Visiting Scholar in the Department of Engineering at the Australian National University (ANU) from 2008 to 2009. He has been involved in Paper Review Committees as an Editorial Board Member of the international journals such as JHM, AJOR, APMR, IJPE etc. He is currently a Professor in the Department of Healthcare Management at Gwangju University. His research interests include intelligent systems development, AI applications in decision analysis and integrated traffic management, and others.

E-mail: jko@gwangju.ac.kr 